\title{
DEVELOPING AN OPEN ACCESS BIM OBJECTS LIBRARY: A HONG KONG STUDY
}

\author{
Weisheng $\mathrm{Lu}^{1}$, Ke Chen ${ }^{2}$, Jing Wang ${ }^{3}$, and Fan Xue ${ }^{4}$
}

\begin{abstract}
Design in a Building Information Modelling (BIM) environment, in a sense, is similar to playing Lego; a designer puts various objects together to form his/her design. The availability of BIM objects, or say the Lego pieces, is one of the most critical issues for promoting BIM implementation. Existing BIM objects, however, are far from comprehensive. Neither is there a 'one-size-fits-for-all' objects library; one has to develop a localised library suiting a particular construction setting. The efforts to tailor-make such a library incur huge costs, which partly explains the mundane BIM implementation in many economies. This paper explores an effective approach to develop an open access BIM objects library focusing on Hong Kong. It does so by (a) determining an ontology-based structure of the library; (b) defining the BIM objects parameters; (c) developing an object processing module (OPM) to unify and integrate the objects from other sources; and (d) exploring the sustainable development of the library. Although further studies are desired to bring it into full reality, the BIM objects library is expected to facilitate building design and information management in a BIM environment. It will also promote BIM implementation in Hong Kong and serve as useful references for other economies.
\end{abstract}

Keywords: BIM objects library, open access, conceptual model, domain ontology.

\section{INTRODUCTION}

The development of Building Information Modelling (BIM) has continuously attracted the attention of business executives, professionals, scholars, policy-makers, and the like. Indeed, organizations around the world deem BIM as a strategic opportunity and are endeavouring to promote its implementation in architecture, engineering, and construction (AEC) projects. Nevertheless, despite the enthusiastic promotion, the euphoria around BIM uptake is yet to be seen. Amongst the many hurdles, a critical one is the lack of a comprehensive BIM objects library to support the object-based parametric design and subsequent project delivery strategies.

In developing a Building Information Model (BIM), designers would drag various objects from a library (Eastman et al. 2011) and add extra semantics (e.g., materials) and topological information (e.g., a beam is resting on a column). In a sense, the process is similar to playing Lego. The issues here are relating to the Lego pieces - the BIM objects. Apparently, the availability of the BIM objects lies in the critical path towards widespread BIM implementation (Sebastian 2011). Without the readily available well-defined objects,

1 Associate Professor, Department of Real Estate and Construction, The University of Hong Kong, Hong Kong, Email: wilsonlu@hku.hk;

2 PhD Candidate, Department of Real Estate and Construction, The University of Hong Kong, Hong Kong, Email: leochen@connect.hku.hk;

3 PhD Student, Department of Real Estate and Construction, The University of Hong Kong, Hong Kong, Email: jingww@connect.hku.hk;

4 Research Assistant Professor, Department of Real Estate and Construction, The University of Hong Kong, Hong Kong, Email: xuef@hku.hk. 
designers have to draw all the objects from scratch and form them into a BIM. This would be costly, burdensome in a real-life project which contains millions of objects of this kind.

This situation has given rise to the need to develop a library of BIM objects with welldefined parameters and rich semantics. In this study, a working definition of the open access BIM objects library is proposed as:

A digital database of semantically rich parametric BIM objects (the major components of buildings such as doors, walls, beams and MEP ducts or pipes) that are contributed by open access sources, unified to the specific parameter format, and integrated into a welldefined library structure.

There have been growing interests in this topic after Autodesk Revit first presented the idea of families as the primary elements for BIM. Several BIM objects catalogues have been developed, such as a library of windows and built-in furniture with changeable size, work tolerance and reference planes (Lee and Lim 2012), and a civil structure library built on 2D drawings (Moon and Ju 2014). These libraries, with confined types and parameters of objects, are not comprehensive enough to support the implementation of BIM in many contexts during project life-cycle.

Commercial BIM software packages such as Autodesk Revit provide some basic building objects (called system families) organized in a library; private and public residential projects develop different sets of objects (e.g., windows or MEP objects), so do some material manufacturers/vendors. However, they are far from comprehensive (Duddy et al. 2013); neither is there an "One-size-fits-all" library suitable for various specific construction contexts (Sulankivi et al. 2009). For example, they are barely useful to Hong Kong's AEC industry which adopts a British Standard (BS) but with its unique building features (e.g., high-rise, concrete-steel composite structures) that require a unique set of BIM objects. Also, the object sets, with consistent data formats, are not always available to ordinary BIM users; this is at the odds of BIM spirit to encourage sharing and communication amongst AEC stakeholders.

To develop the BIM objects library, three key issues should be taken into consideration: the library structure, object attributes, and sources to comprehensively acquire objects (Duddy et al. 2013). These could be achieved through a review on literature, BIM software handbooks (Kang et al. 2012), 2D shop drawings (Lee and Lim 2012), and existing construction classification systems (Afsari and Estman 2016). When operationalizing, some add-in tools of commercial software enable users to define objects. For example, BIM users could define the families (set of objects) through Autodesk Revit and reuse them later in other projects. This method does enrich the library to meet the ever-changing needs of the industry. However, it is notoriously tedious, laborious and costly to evolve the considerable manual efforts.

This paper aims to explore an effective approach to establish an open access BIM objects library. Several specific objectives are designated to achieve this aim:

1. determining a structure of the BIM objects library built on ontology;

2. defining the BIM objects that meet the regulations of Hong Kong construction context (e.g. the British Standard [BS] and Hong Kong's construction needs);

3. developing a cost-effective object processing module (OPM) to unify and integrate BIM objects from multiple sources to the library; and

4. sharing the library (i.e. making it open access to ordinary users) and achieving its responsibilities in the industry. 
The following Section 2 presents a conceptual model to describe the key challenges and four steps to develop the BIM objects library. The potential applications and future research directions are discussed in Section 3, followed by conclusions in Section 4.

\section{DEVELOPMENT OF AN OPEN ACCESS BIM OBJECTS LIBRARY}

One of the major hurdles is that there is no widely applicable BIM library. We have to develop a tailor-made library for specific construction needs, e.g. in Hong Kong. This study builds itself on a very innovative perspective, i.e. these objects, no matter in different appearances, materials or locations, are actually different clusters of information (e.g., geometry, semantics, and topological information) as recognized by the library, BIM software, and computers. Thus, developing BIM objects library is translated into a series of challenges to define its three key elements, enrich the library and share it in the industry (Figure 1). The key library elements include the BIM objects (i.e. the object information and its format), a structure to accommodate the objects, and the object relationships. To enrich the library, the OPM is developed to unify and integrate the object attributes from multiple open sources (e.g. existing BIM library). Also, the developed library could be shared in the industry to maintain its sustainable development. Each of the challenges will be discussed in detail in the following sections.

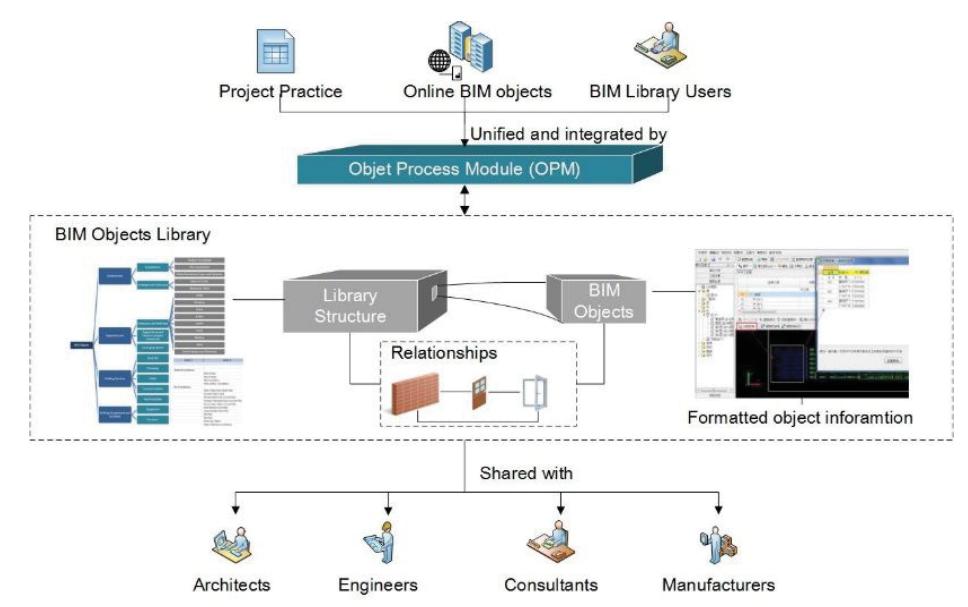

Figure 1: A conceptual model to develop the open access BIM objects library

\subsection{Determining a Library Structure Built on Ontology}

The library structure is more than just a classification system; it divides a collection of objects in mutually exclusive, hierarchical sets consisting of members with one or many common properties (Ekholm and Haggstrom 2011). To facilitate wider BIM applications, the library structure should also be able to organize the objects and indicate their relations with clarity, coherence, comprehensiveness, extensibility, minimal encoding bias and minimum commitment. Therefore, it is necessary to harness the domain ontology of BIM objects for theoretical foundations, and existing classification systems and Hong Kong building codes to meet the needs of Hong Kong local market.

\subsubsection{Domain ontology of BIM objects.}

The domain ontology of BIM objects is crucial in developing a structural and comprehensive library. It presents the taxonomic hierarchies of classes, class definitions and subsumption relations by defining terms, definitions, attributes, classes, and hierarchies of BIM objects (Gruber 1993, 1995). In this way, human knowledge on BIM 
objects can be linked to web knowledge and processed by machine (Huang et al. 2010). There are various methods to develop the ontology, such as Toronto Virtual Enterprise (TVE) approach and the Enterprise Model approach (Jone et al. 1998). Despite considerable differences among these methods, they share many steps in common such as defining scope, researching relevant ontologies, documenting and integrating domain terms. All the knowledge could be applied to develop the domain ontology of BIM objects.

\subsubsection{Knowledge Acquisition to Develop the Library Structure}

An essential step is to acquire knowledge from relevant ontologies, classification systems, local building codes/specifications/regulations, and interviews with experts. Existing classification systems summarize and organize available knowledge in a structured way (Afsari and Eastman 2016). For example, OminClass classifies objects meeting the British Standard; the UniFormat II Elemental Classification and MasterFormat of North America also serve as importance references for defining a structural classifications system in Hong Kong. However, the objects in these classification systems are not always directly related to BIM; therefore, it is necessary to have a clear and detailed review of BIM-related books, papers, standards as well as local building codes/specifications/regulations to satisfy the needs of BIM and Hong Kong market. Expert interviews could also be conducted to ensure that the documented terms are adequately comprehensive.

\subsubsection{A Preliminary Structure of the BIM Objects Library}

A preliminary structure of the BIM objects library (Figure 2) contains four levels of BIM objects. Level 1 identifies Major Objects (MOs) such as Substructure, Superstructure, Building Services and Building Equipment and Furniture. Level 2 breaks the MOs into Group Objects (GOs), Level 3 further subdivides GOs into Individual Objects (IOs), and Level 4 provides examples of Level 3 IOs in different configurations. For example, Substructure could be classified into Underground Enclosures and Foundation; the latter one contains Shallow Foundations, Pile Foundations and Other Foundation Types and Elements in Level 3 Classes; and examples of Shallow Foundations include pad footings, strip footings, raft footing and the like in Level 4.

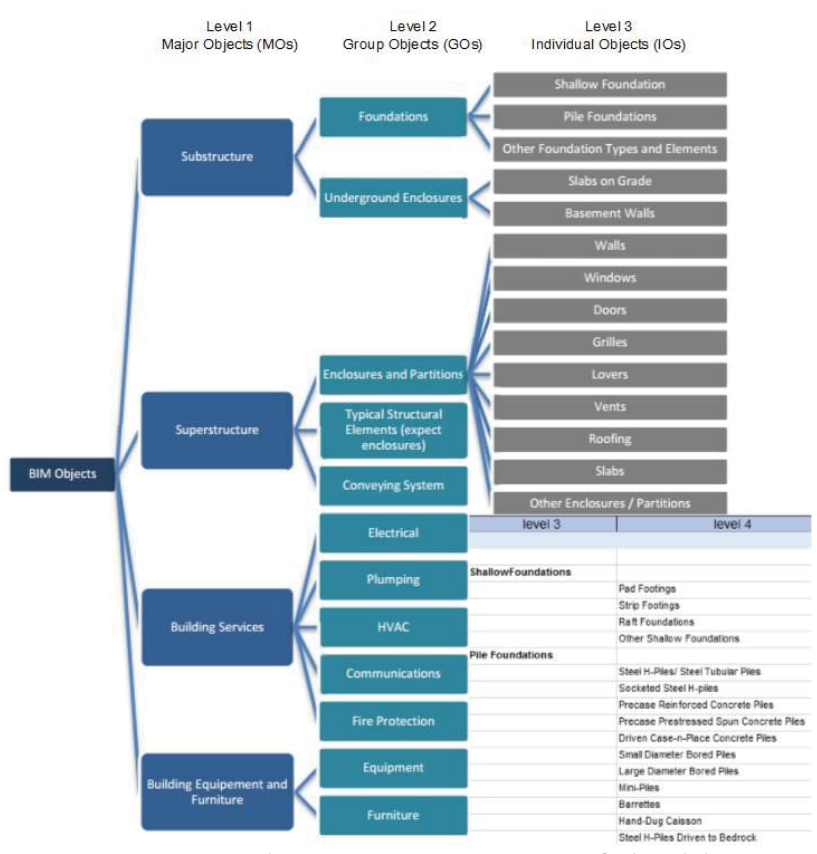

Figure 2: A preliminary structure of the library 


\subsection{Defining the Objects Meeting the Specific Construction Needs}

As mentioned, the BIM objects should be more than just a graphical representation of the physical building object, but a cluster of information needed in the project lifecycle. In a sense, the crux to define the objects lies in the definition of objects information, the parameter templates and the information format that meet the BS and Hong Kong construction needs. To develop semantically rich BIM objects, data could be collected from two sources: interview probing into the industry needs, and desktop studies of existing BIM standards and objects libraries.

\subsubsection{Data Collection via Interviews}

Semi-structured interviews with representatives from AEC firms in Hong Kong could be conducted to collect data of BIM object parameters. The questions for the semi-structured interviews comprise of two parts. The first part is designed to collect the basic information of interviewees, including their job descriptions and experience in using BIM. The second part is designed to identify BIM objects and their parameters required by the interviewees. Example questions include "What BIM objects you have used in your works?", "What parameters of these objects are important to you?", and "Whether (one parameter) is important or not?". During the interviews, the interviewees are encouraged to express their views on specific BIM objects or specific object parameters used in daily works.

\subsubsection{Data Collection via Desktop Studies}

The desktop studies include but not limit to the existing British and Hong Kong BIM standards, guidelines, literature, and building codes to understand the point of departure and to avoid 'reinventing-in-the-wheel'. So far, Hong Kong government and organizations have published several BIM standards and guidelines, such as BIM Library Components Design Guide by Hong Kong Housing Authority (HKHA), and CIC BIM Protocol published by Construction Industry Council in 2013. In addition, Hong Kong has three sets of BIM standards. We will screen these BIM standards and guidelines, and record all regulations or suggestions related to BIM objects and their parameters.

To facilitate information exchange, the identified object parameters are integrated by referencing to the IFC4 Add2 schema, which is developed by buildingSMART to present object parameters and their relationship. However, the current IFC4 Add 2 schema may not be comprehensive enough to cover all necessary object parameters of Hong Kong contents. Therefore, when defining the object parameter sets, the IFC4 Add2 schema could be expanded to accommodate the ever-changing industrial needs.

\subsubsection{A Preliminary Structure of Parameter Templates of BIM Objects}

A preliminary parameter template of BIM objects is shown in Figure 3, which is better read in conjunction with Figure 2 above. It is suggested that the object parameters can be broadly categorized into four types: the product, process, behaviour and impact, and constraint parameters. The Product parameters describe the physical characteristics of the objects per se, such as Identifications, Geometry, Spatial Parameters, Constitutions, and Material. The process parameters indicate the Level of Development (LOD), and the necessary information in different phases of projects, e.g. planning, design, procurement, construction, etc. The Behaviours and Impacts are the objects' functions and potential influence on other objects, building projects and the environment, such as costs and schedule. The Constraint parameters describe the spatial requirements and building specifications and standards that confine the objects. It should be noticed that the different 
sets of object parameters are interconnected with one another to facilitate building design and information utilization and interoperability.

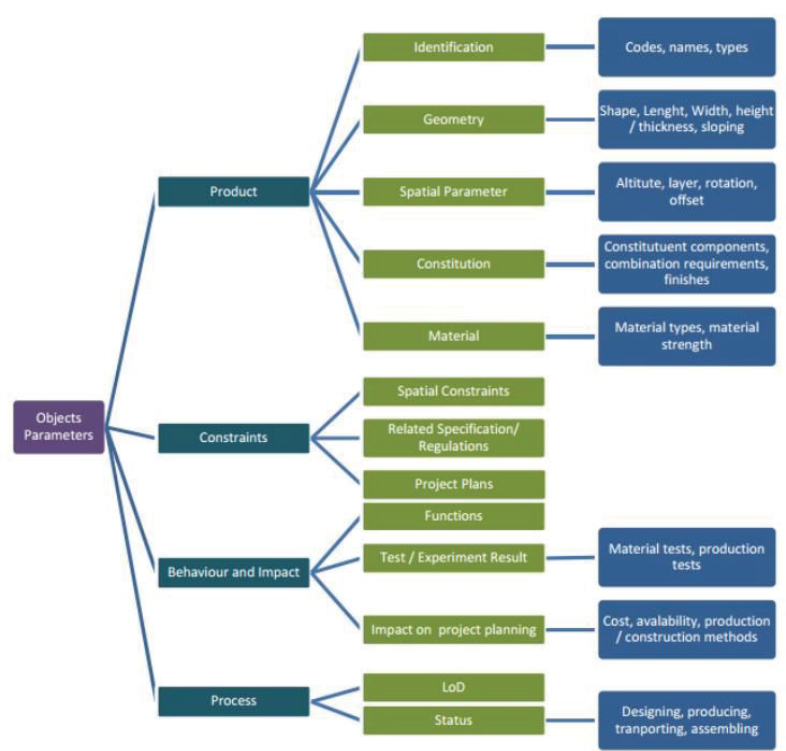

Figure 3: A preliminary structure of parameter templates of the BIM objects

\subsection{Enriching the Objects Library Using Object Processing Module}

The object processing module (OPM) is a processing unit to unify the objects parametric information and integrate the objects into the library. Currently, BIM objects for Hong Kong AEC industry come from multiple sources, including project practices, BIM users and existing BIM objects libraries. For example, the (UK) National BIM Library owned by the Royal Institute of British Architects (RIBA) (https://www.nationalbimlibrary.com/) offers over 6,500 BIM objects in 150 categories; the downloaded object contains both the object files in IFC and/or RVT format and a text file for its specific parameters. Considering the massive objects to operate, it is extremely time-consuming and labourintensive to manually integrate all the required BIM objects in the library structure. Thus, innovative OPM that can automatically modify existing objects' parameters and integrate them into the library are highly desired.

The process of developing the OPM is quite straightforward. Since BIM objects from multiple sources do not always contain the same type of information, these objects should be analysed first to identify their parameters, terminology used, and information format. By comparing the information (e.g. geometry, material, manufacturer, etc.) of the processing object with that of the existing library objects, the OPM can verify whether the objects are identical and make decisions to include/exclude the processing objects from the library. A validation object set will be created with a number of manually classified entries, on which the OPM will be tested in terms of the precision and recall. Then, the OPM will automatically modify (i.e., add or delete) the object parameters, unify the terminology, and standardize the data format. The underpinning rationale is similar to goal programming (GP), which extents linear programming to handle multiple objectives (Charnes and Cooper 1977). The objects library prototype will be developed for users to collect and share qualified BIM objects in Hong Kong context. The front-end of the object library consists of layout, navigation, and dynamic parts, which should be carefully designed to ensure the ease of use. The back-end of the object library will run in a cloud environment, with tailor-made database and applications. 


\subsection{Sharing the Library and the Responsibilities in the Industry}

The proposed open access BIM objects library could be very useful for Hong Kong AEC firms in a long-term period provided it is developed in a sustainable fashion. For example, while users benefit from the open access BIM objects, they should also contribute to them to maintain its sustainability. In Hong Kong, two lines of strategies could be adopted. The first method relates to create a 'value network' where the different AEC firms are engaged in knowledge dissemination activities for further value creation in their own business. This would be achieved through carrying out relevant research activities and initiating collaborations between the research team and the industry. The other method is to seek opportunities to work closely with government or professional bodies, e.g., the Hong Kong Housing Authority (HKHA) and the Hong Kong Construction Industry Council (HKCIC) to share the object library in the industry. When this object library is well accepted by the industry, the operation modes should be further explored to maintain the substantiality of the open access library.

\section{DISCUSSIONS}

The library developed in this study could significantly increase the efficiency and accuracy of using BIM. It provides comprehensive and information-rich objects that could be directly used by BIM designers by simply adding extra text-based information according to the parameter templates. The adding parameters, subsequently, could be checked against pre-defined constraints such as spatial relationships and Hong Kong building regulations to ensure their quality. Additionally, the library supports information management and utilization in the subsequent stages. BIM users could customize the parameters of the objects to achieve various applications of the library, such as preliminary cost estimation, scheduling, energy analysis, and the like.

The research could also offer significant implications to develop BIM objects libraries in other economies, such as Mainland China, which adopts a GuoBiao (GB) system and has its own AEC needs in BIM. This could be achieved by following the four steps to develop BIM objects library, with a modification of library structure, objects parameter templates and the OPM derived from this study to tailor the standards and AEC needs of the other economics.

However, there are still various challenges to be overcome to bring the open access BIM objects library into practice. First, a more detailed and comprehensive library structure and parameter template should be explored, based on an in-depth study on domain ontology of BIM objects. Future efforts should be also made to explore the operation modes to maintain the substantiality of the proposed object library.

\section{CONCLUSIONS}

In the environment of BIM, the set of semantically rich BIM objects is probably the most fundamental part in the BIM-enabled design and information management. The lack of such comprehensive collection of the objects to ordinary BIM users is one of the most critical factors explaining the lukewarm BIM implementation in Hong Kong. This paper, by proposing a conceptual model to semi-automatically develop such a library, has both practice significance and academic merits. With such an open access BIM objects library, users can significantly reduce the 'unit cost' to put information into BIM; that could boost BIM implementation and information sharing in the industry. Such experience of 
developing BIM objects library in Hong Kong is also valuable to other economies over the world. In addition to obvious practical benefits, this research also has significant academic merits. Attempts to improve BIM ontology, perceive BIM's essence from an information and its cost perspective, define BIM objects as a cluster of information, and explore automatic ways to draw BIM objects are all fundamental research frontiers pursued by BIM research teams around the world. To harvest the maximal benefits of the proposed BIM objects library, future research could be undertaken towards a more comprehensive structure and object parameters of the library, an innovative OPM to enrich the library, and potential application scenarios of the library.

\section{REFERENCES}

Afsari, K. and Eastman, C.M. (2016). A Comparison of Construction Classification Systems Used for Classifying Building Product Models. In the 52nd ASC Annual International Conference Proceedings.

Charnes, A. and Cooper, W.W. (1977). Goal programming and multiple objective optimizations: Part 1. European Journal of Operational Research, 1 (1), pp.39-54.

Duddy, K., Beazley, S., Drogemuller, R. and Kiegeland, J. (2013). A platform-independent product library for BIM. In Proceedings of the 30th CIB W78 International Conference, pp.389-399.

Eastman, C.M., Teicholz, P., Sacks, R. and Liston, K. (2011). BIM handbook: A guide to building information modeling for owners, managers, designers, engineers and contractors. John Wiley \& Sons.

Ekholm, A. and Häggström, L. (2011). Building classification for BIM-Reconsidering the framework. In CIB W78-W102 2011: International Conference. CIB.

Gruber, T.R. (1993). A translation approach to portable ontology specifications. Knowledge acquisition, 5 (2), pp.199-220.

Gruber, T.R. (1995). Toward principles for the design of ontologies used for knowledge sharing?. International journal of human-computer studies, 43 (5), pp.907-928.

Huang, C.R. (2010). Ontology and the lexicon: a natural language processing perspective. Cambridge University Press.

Jones, D., Bench-Capon, T. and Visser, P. (1998). Methodologies for ontology development.

Kang, T.W., Lee, J.W., Lee, W.S. and Choi, H.S., 2012. A study on civil BIM description neutral library development direction for modeling the construction spatial information. Journal of Korean Society for Geospatial Information System, 20 (4), pp.145-151.

Lee, C.J. and Lim, S.H. (2012). A Study on Development of BIM Library for Unit Modular Housing-Focused on Small-sized Urban-life-housing. Journal of the Korean housing association, 23 (6), pp.11-20.

Moon, H. and Ju, K. (2014). Development of BIM Library for Civil Structures based on Standardized Drawings-Focused on 2D Standard Drawings of The MOLIT. Transactions of the Society of CAD/CAM Engineers, 19 (1), pp.80-90.

Sebastian, R. (2011). Changing roles of the clients, architects and contractors through BIM. Engineering, Construction and Architectural Management, 18 (2), pp.176-187.

Sulankivi, K., Makela, T. and Kiviniemi, M. (2009). BIM-based site layout and safety planning. In Proceedings of the First International Conference on Improving Construction and Use through Integrated Design Solutions. 